\title{
A unique case of kidney's collecting system MALT lymphoma
}

\author{
Seyed Alaeddin Asgari, MD; Hamidreza Baghani Aval, MD; Seyed Ali Asgari, MD; Keyvan Kheradmand, MD
}

Urology Research Center, School of Medical, Guilan University of Medical Sciences, Razi Hospital, Rasht, Iran

Cite as: Can Urol Assoc J 2014;8(3-4):e172-5. http://dx.doi.org/10.5489/cuaj.1452

Published online March 11, 2014.

\section{Abstract}

Low-grade B cell lymphomas of mucosa-associated lymphoid tissue (MALT lymphomas) are mostly seen in the gastrointestinal tract. MALT lymphomas involving kidney are extremely rare. We report on a case of MALT lymphomas of the kidney. A 74-yearold woman presented with an episode of gross hematuria and right flank pain. In renal sonography, we found a hypoecho lesion measuring $61 \times 58 \times 44 \mathrm{~mm}$ in the lower pole of right kidney. A computed tomography scan revealed an enlarged hypodense soft tissue measuring $62 \times 42 \times 37 \mathrm{~mm}$ within the pelvic brim of the right kidney, with extension to the proximal portion of the ipsilateral ureter and engulfed it. The patient underwent a right radical nephrectomy. The pathology specimen indicated a lymphoprolifrative disorder involving the kidney and ureter. To obtain a definitive diagnosis, we used an immunohistochemistry, which confirmed the diagnosis of a MALT lymphoma.

\section{Introduction}

Low-grade B cell lymphomas of mucosa-associated lymphoid tissue (MALT lymphomas) is mostly seen in the gastrointestinal tract. ${ }^{1}$ MALT lymphomas involving kidney are extremely rare; the first was reported by Pelsdving and colleagues in $1991 .^{2-3}$

Primary renal lymphoma typically presents at age 40 with flank pain, weakness, weight loss, hematuria, malaise, abdominal mass or renal failure. ${ }^{4-5}$ The kidney does not have lymphoid tissue, but repetitive injuries to renal lymphatics due to chronic inflammation may cause malignant transformation to neoplasia of the lymphoid tissue. This occurs in extra nodal MALT lymphoma, which affects the skin, the gastrointestinal tract and the breast. ${ }^{5-7}$

\section{Case report}

A 74-year-old woman presented with an episode of gross hematuria and right flank pain. She had a history of stones in the right kidney, which had been treated 3 years ago by shock wave lithotripsy (SWL). In the kidney, ureter, bladder (KUB) scan and sonography follow-up after the SWL, there was not any evidence of residual stones. Her medical history was unremarkable. Physical examination findings were normal. In laboratory tests, complete blood cell (CBC) and blood chemistries, including liver function tests, were normal. Renal function tests were also normal (creatinine: $1.3 \mathrm{mg} / \mathrm{dL}$, blood urea nitrogen: $15 \mathrm{mg} / \mathrm{dL}$ ). Urine analysis revealed no hematuria or puria. In renal sonography, a hypoecho lesion $61 \times 58 \times 44 \mathrm{~mm}$ in the lower pole of right kidney was seen that had distorted lower and middle calyces. There was also a bilateral mild hyponephrosis. For the complete workup of hematuria, we performed a cyctoscopy and abdominopelvic computed tomography (CT) scan. Cyctoscopy findings were normal. A CT revealed an enlarged hypodense soft infiltrative lesion measuring $62 \times 42 \times 37 \mathrm{~mm}$ within the pelvic brim of the right kidney, with extension to the proximal portion of ipsilateral ureter and engulfed it. Contrast injection showed minor enhancement. We noticed minor dilation of the pelvic brim of the left kidney (extra renal pelvic) with no evidence of any stone within both-kidneys, ureters or bladder (Fig. 1a, Fig. 1b, Fig. 1c, Fig. 1d).

Infiltrative appearance of the lesion in CT (Fig. 1a, Fig. 1b, Fig. 1c, Fig. 1d) and medially location of the kidney mass caused a large technical challenge for biopsy. The patient underwent right radical nephrectomy. The pathology specimen indicated a lymphoprolifrative disorder involving the kidney and ureter (Fig. 2). To obtain a definitive diagnosis, we used an immunohistochemistry (IHC), which confirmed the diagnosis of a MALT lymphoma. IHC study showed CD5, CD20 and BCL2 all positive and CD3 negative; therefore, a MALT lymphoma was confirmed. The patient was referred to an oncologist for adjuvant chemotherapy. 


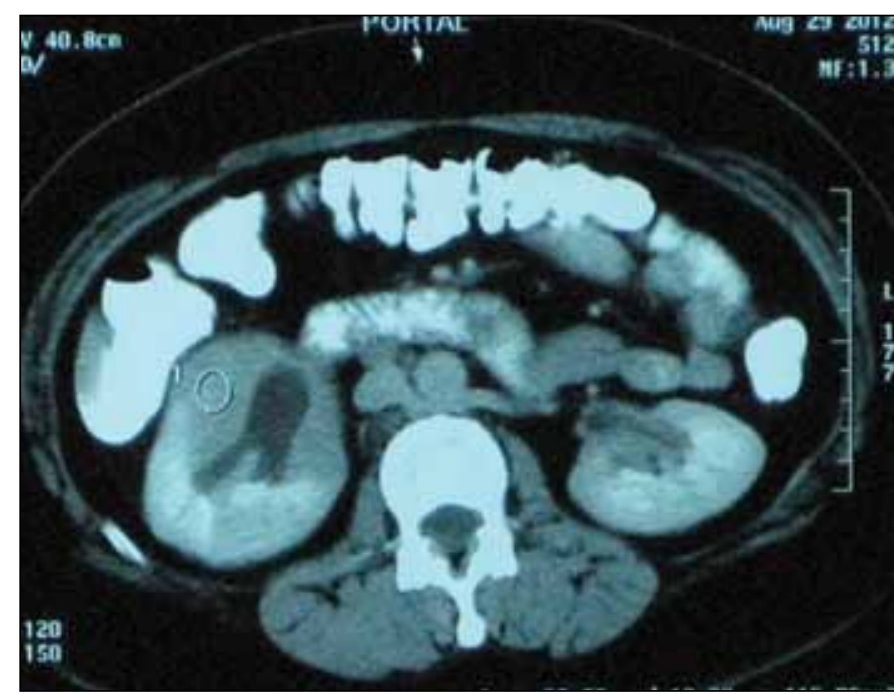

Fig. 1a. Abdominal computed tomography scan with intravenous and oral contrast reveals an enlarged hypodense soft infiltrative lesion within pelvic of right kidney with extension to proximal portion of ipsilateral ureter and engulfed it.

\section{Discussion}

Renal involvement by B cell lymphoma represents a manifestation of non-Hodgkin lymphoma. Renal lymphoma can be either primary or associated with external lymphoma. ${ }^{8-9}$

Primary renal lymphoma typically presents in age above 40, with flank pain, weakness, weight loss, hematuria, abdominal mass or renal failure. ${ }^{4-5}$ Kidney does not have lymphoid tissue, ${ }^{10}$ but repetitive injury to renal lymphatics due to chronic inflammation may cause malignant transformation to neoplasia of the lymphoid tissue. This occurs in extra nodal MALT lymphoma, which affects the skin, the gastrointestinal tract and the breast..$^{5-7,11}$ However, renal MALT lymphoma is rare. ${ }^{12}$

Diagnosis is a challenge; it is sometimes difficult to distinguish MALT lymphomas from more common tumours, such as renal cell carcinoma (RCC), in imaging studies; diagnosis, however, can be confirmed with a CT-guided biopsy of the mass. ${ }^{4}$ In most cases, diagnosis is made after radical nephrectomy for the suspected RCC. MALT lymphomas can be treated with chemotherapy, surgical intervention or radiotherapy. ${ }^{13}$

Chemotherapy is the foundation of treatment, especially for controlling systemic disease; ${ }^{8}$ early proper treatment correlates with improved outcome. Patients with MALT lymphomas have a better prognosis compared with patients with a higher grade lymphomas.

Cueto and colleagues reported a case of MALT lymphoma and RCC. ${ }^{3}$ This report reminds us that all solid enhancing renal masses are not RCC. As therapy may be greatly affected by a different diagnosis, this case further supports the role of renal biopsy in unusual lesions. Although, in our case, the infiltrative appearance of the lesion in CT and the medial location of the kidney mass, we were technically hampered in performing the biopsy.

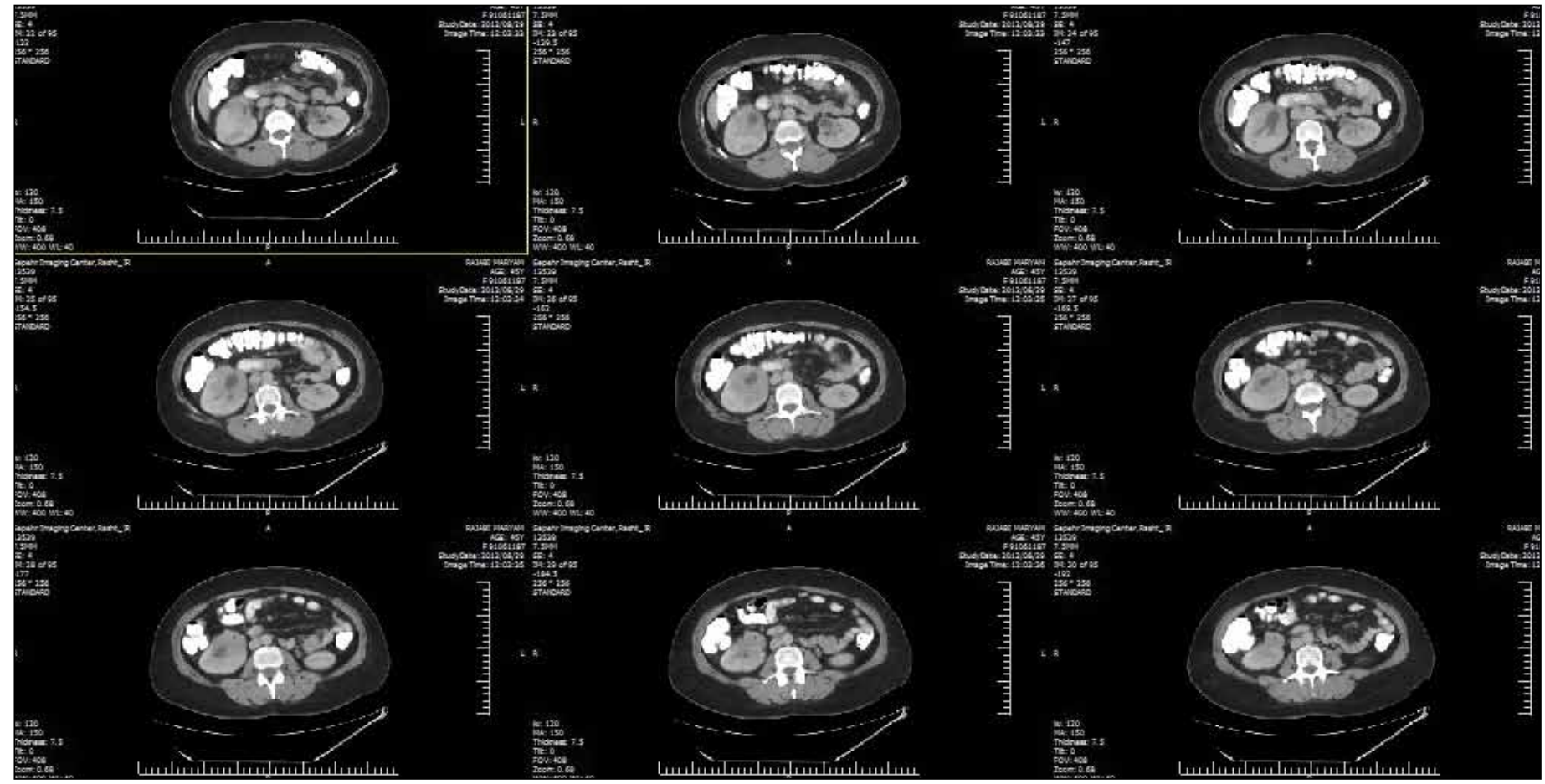

Fig. 1b. Abdominal computed tomography scan with intravenous and oral contrast reveals an enlarged hypodense soft infiltrative lesion within pelvic of right kidney with extension to proximal portion of ipsilateral ureter and engulfed it. 


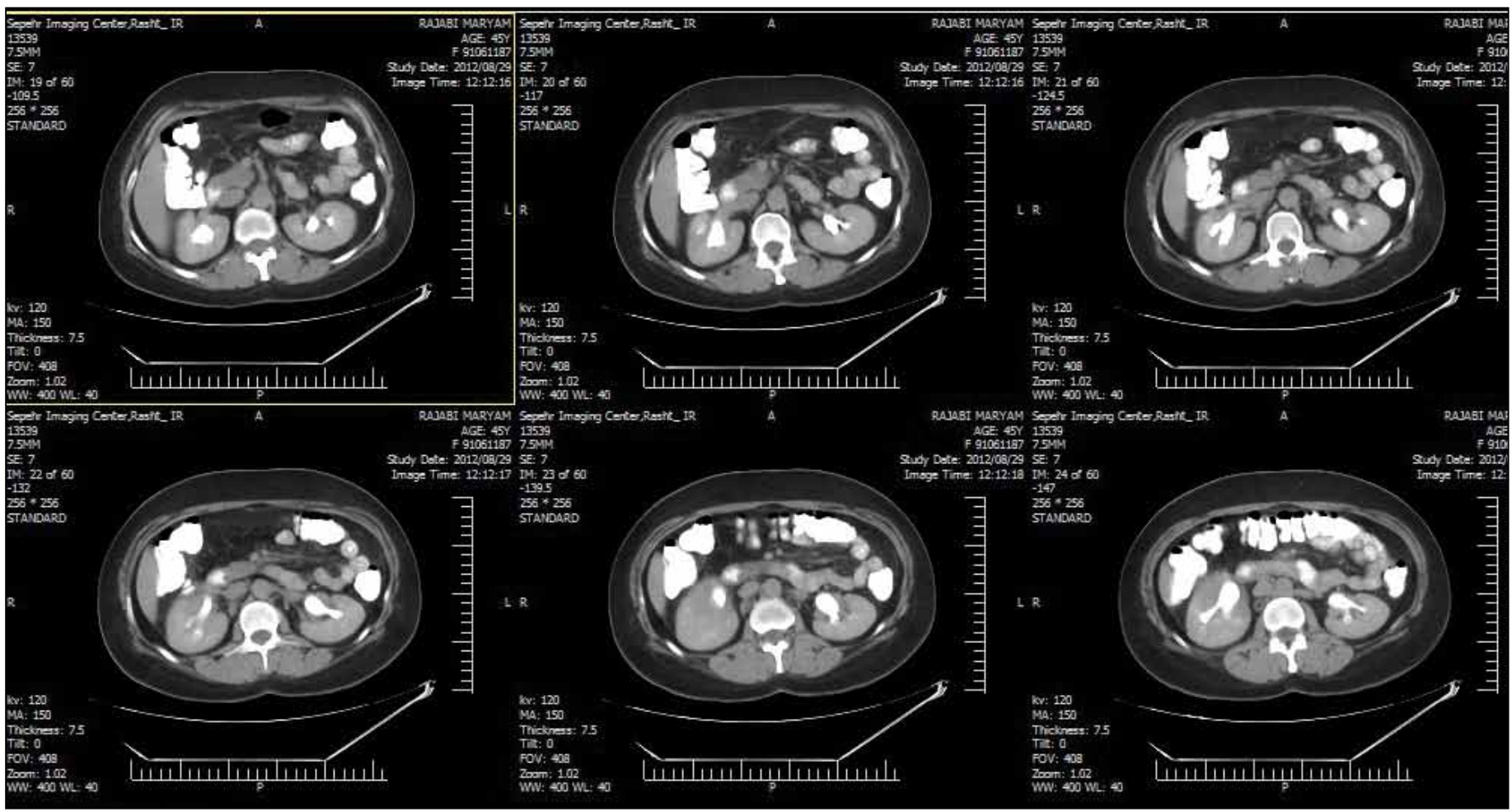

Fig. 1c. Abdominal computed tomography scan with intravenous and oral contrast reveals an enlarged hypodense soft infiltrative lesion within pelvic of right kidney with extension to proximal portion of ipsilateral ureter and engulfed it.

\section{Conclusion}

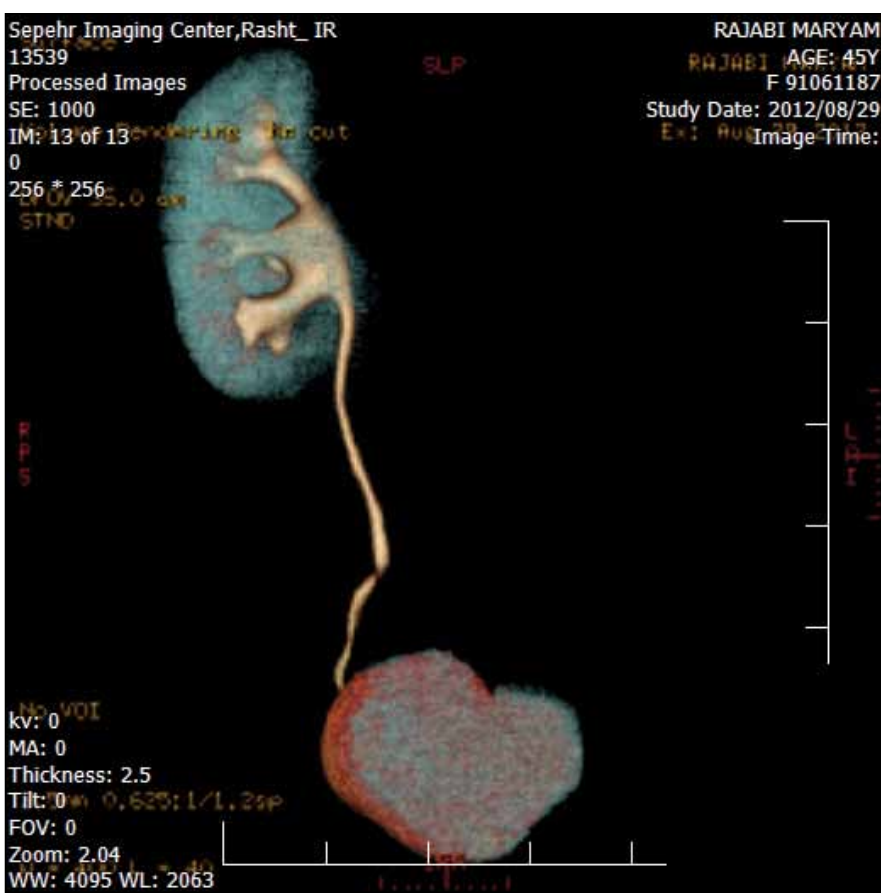

Fig. 1d. Abdominal computed tomography scan with intravenous and oral contrast reveals an enlarged hypodense soft infiltrative lesion within pelvic of right kidney with extension to proximal portion of ipsilateral ureter and engulfed it.
MALT lymphoma is rare in patients with renal mass. Early diagnosis and proper treatments are cornerstones for favourable prognosis. MALT Iymphoma, like the other types of

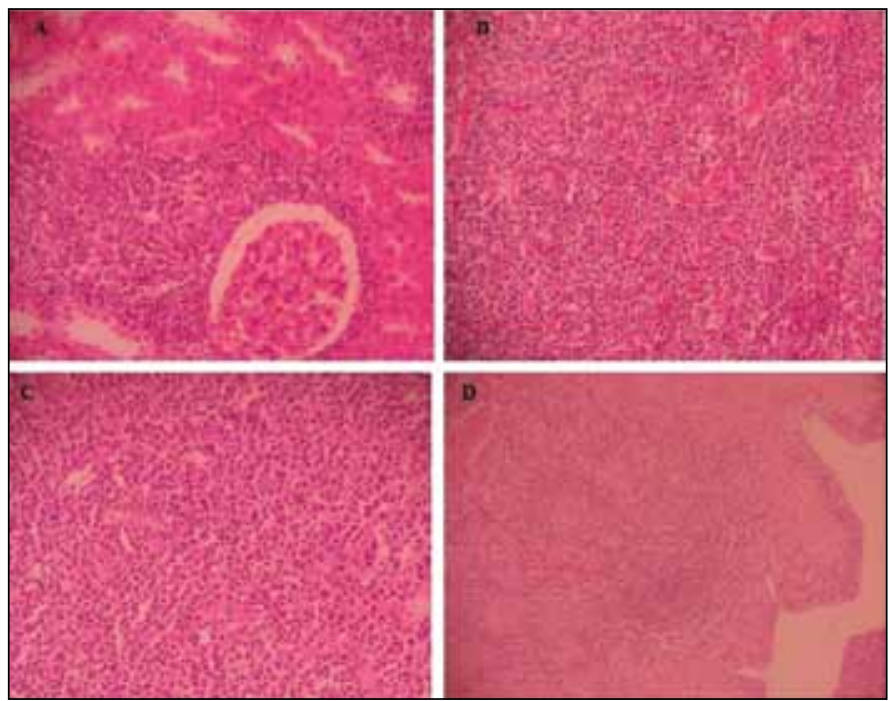

Fig. 2. The histopathologic sections show cortical \& especially medullary tissue in which replaced by mixed populations of lymphocytes, many plasma cells \& scattered large atypical cells. These cells extend into cortical parenchyma and renal pelvis with sparing of renal glomeruli. The ureter involves by inflammatory [magnifications: $A, B, C(\times 10), D(\times 5)$ ]. 
lymphoma, is chemosensitive. Early treatment begets a favourable outcome.

Competing interests: Dr. Asgari, Dr. Aval, Dr. Asgari and Dr. Kheradmand all declare no competing financial or personal interests.

This paper has been peer-reviewed.

\section{References}

1. Chi PJ, Pei SN, Huang TL, et al. Renal MALT lymphoma associated with Waldenström macroglobulinemia. J Formosan Med Assoc 2011; hitp://dx.doi.org/10.1016/i.jma.2011.02.007

2. Pelstring RJ, Essell JH, Kurtin PJ, et al. Diversity of organ site involvement among malignant lymphomas of mucosa-associated lymphoid tissues. Am JClin Pathol 1991;96:738-45.

3. Cueto PJM, Cuevas LA, Cauqui RG, et al. Synchronous kidney neoplasms: Renal carcinoma, clear cells type, and B lymphoma, low grade, MALT type. Rev Esp Patol 2009;42:70-2.

4. Kose F, Sakalli H, Mertsoylu H, et al. Primary renal lymphoma: Report of four cases. Onkologie 2009;32:200-2. http://dx.doi.org/10.1159/000203331

5. Hart S, Ellimoottil C, Shafer D, et al. A case of primary renal lymphoma. Urology 2012;80:763-5. http:// dx.doi.org/10.1016/j.urology.2012.05.017
6. Freeman C, Berg JW, Cutter SJ. Occurrence and prognosis of extranodal lymphomas. Cancer 1972;29:252-60. http://dx.doi.org/10.1002/1097-0142(197201)29:1<252::AlD-CNCR2820290138>3.0.C0;2\#\#

7. Salem Y, Pagliaro LC, Manyak MJ. Primary small noncleaved cell lymphoma of kidney. Urology 1993;42:331-5. http://dx.doi.org/10.1016/0090-4295(93)90627-M

8. Al-Salam $S$, Shaaban A, Alketbi $M$, et al. Acute kidney injury secondary to renal large B-cell lymphoma: Role of early renal biopsy. Int Urol Nephrol 201 1;43:237-40. http://dx.doi.org/10.1007/s11255010-9728-5

9. Yasunaga $Y$, Hoshida $Y$, Hashimoto $M$, et al. Malignant lymphoma of the kidney. J Surg Oncol. 1997;64:207-11. http://dx.doi.org/10.1002/(SICI) 1096-9098(199703)64:3<207::AIDJSO6>3.0.C0;2-E

10. Gellrich J, Hakenberg OW, Naumann R, et al. Primary renal non-Hodgkin's lymphoma-a difficult differential diagnosis. Onkol 2002;25:273-7. http://dx.doi.org/10.1159/000064322

11. Cortot AB, Cottin V, Issartel B, et al. Pulmonary MALT lymphoma revealing AIDS. Rev Mal Respire 2006;23:353-7. http://dx.doi.org/10.1016/S0761-8425(06)71602-3

12. Jindal B, Sharma SC, Das A, et al. Indolent behavior of low-grade B cell lymphoma of mucosa associated lymphoid tissue arising in the kidney. Urol Int 2001;67:91-3. http://dx.doi.org/10.1159/000050955

13. Wagner JR, Honig SC, Siroky MB. Non-Hodgkin's lymphoma can mimic renal adenocarcinoma with inferior vena caval involvement. Urology 1993;42:720-4. http://dx.doi.org/10.1016/0090-4295(93)90543$\mathrm{JD}$

Correspondence: Dr. Hamidreza Baghani Aval, Urology Research Center, School of Medicine, Guilan University of Medical Sciences, Razi Hospital, Sardar Jangal St., Rasht, Iran; hamidreza_baghani@yahoo.com 